\title{
Research on Speed Sensorless Vector Control System of Asynchronous Motor Based on MRAS
}

\author{
Zili Liao, Qijin Zhao, Xinxi Zhang and Luming Chen \\ Department of Arms and Control Engineering, Academy of Army Armored Force, Beijing, China
}

\begin{abstract}
This paper analysed the basic principle of speed sensorless vector control system. Based on speed and current closed loop vector control, combined with a simple and feasible current hysteresis control strategy, the whole speed sensorless system of asynchronous motor is simulated in MATLAB/Simulink. The method uses the Model Reference Adaptive System (MRAS). The observation and analysis of waveform shows that the system has good static performance and robustness. The control effects are also as similar as the vector control system which contains speed sensor.
\end{abstract}

\section{Introduction}

At present, $\mathrm{AC}$ induction motors have a wide range of applications in the production and life. To achieve better control results, accurate speed feedback is required. Due to the limited reliability and high cost of the current speed sensors (Most of them are photoelectric encoders, resolver, etc.) in harsh environments, it is very important to study the control system of high performance speed sensorless[1-2].

In the sensorless control technology, speed identification is the key. The main methods having been used are direct calculation, Extended Kalman Filter (EKF), model reference adaptive method (MRAS), high frequency injection and intelligent control method[3-4]. By comparing these methods, MRAS is suitable for medium and high speed operation and is easier to implement in practical application[5]. In this paper, on the basis of vector control, build the motor simulation model, and the MRAS based speed estimation method is applied to the model. By observing the simulation results, the motor speed control and speed identification performance have been analyzed.

\section{Vector control strategy based on current hysteresis loop}

\subsection{Current hysteresis PWM control}

Hysteresis current pulse width modulation(PWM) technology is a method of converting the DC voltage into a voltage pulse sequence by using the power switching device. It can achieve the purpose of frequency conversion and voltage variation by controlling the voltage pulse width or period[6]. In the voltage source inverter, the hysteresis current tracking control provides a method to control the transient current output. The basic idea is using output current as the command signal and the actual current as feedback signal, then determine the power switch of the inverter by comparing the instantaneous value of the two switches so that the actual output tracking command signal. Hysteresis current PWM modulation control system is simple relatively. And it is different from the Space vector pulse width modulation(SVPWM) which needing Combination and calculation of complex voltage space vectors[7-8]. It controls the current directly, and the control precision is due to the switching frequency of inverter components and hysteresis width. By setting reasonable hysteresis width, simple direct control of current can be carried out.

In figure 1 , the principle of single phase half bridge inverter circuit for PWM current tracking control is presented.

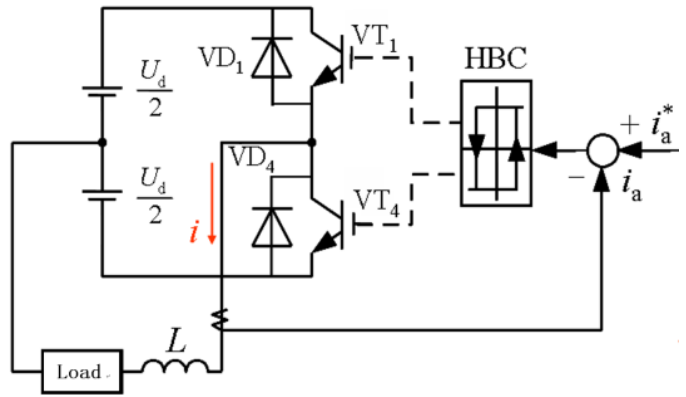

Figure 1. Schematic diagram of hysteresis current tracking control

As shown in figure 1, the deviation $\Delta i_{\mathrm{a}}$ between the given current $i_{a}^{*}$ and the output current $i_{a}$ is taken as the 
input of the comparator with hysteresis characteristics. The on-off of power device $V T_{1}$ and $V T_{4}$ is controlled by its output. When $\Delta i_{\mathrm{a}}$ is positive, the $V T_{1}$ is switched on, and then $i_{a}$ increases and, when the $V D_{4}$ freewheeling, $i_{a}$ decreases. When $\Delta i_{\mathrm{a}}$ is negative, the $V D_{4}$ is switched on, and then the absolute value of $i_{a}$ increases, and when the $V D_{1}$ freewheeling, $i_{a}$ the absolute value of $i_{a}$ decrease. In this way, the current command is tracked in zigzag range in the range of $i_{a}+\Delta I$ and $i_{a}-\Delta I$ by controlling the hysteresis comparator with a ring width of $2 \Delta I$ [9]. The current tracking waveform is shown in figure 2.

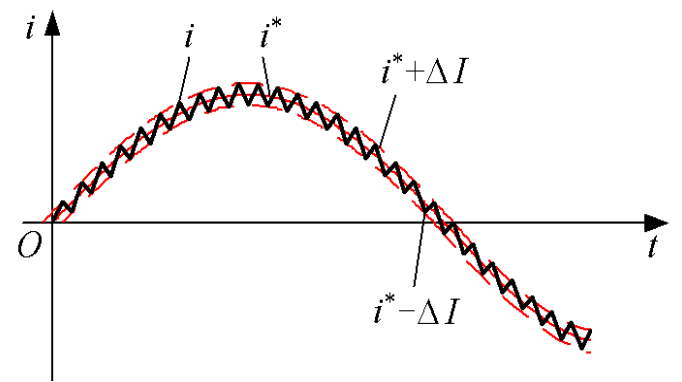

Figure 2. Current waveform in current hysteresis loop tracking control

\subsection{Vector control principle and mathematical model of asynchronous motor}

Vector control decompose the stator current vector of $\mathrm{AC}$ motor into two DC components (magnetic flux component and torque component) through coordinate transformation, so as to realize the decoupling of torque control and flux linkage control of induction motor. In the two-phase system, the d-axis can be regarded as the field winding of the DC motor, $i_{d}$ is equivalent to the excitation current while the q-axis can be regarded as the armature winding, $i_{q}$ is equivalent to the armature current which is proportional to the electromagnetic torque[10]. So that control the d-axis current and q-axis current, so as to achieve the desired control effect and avoid the nonlinear and strong coupling problems.

The equations of the motor in the d-q coordinate system are obtained by Clarke and Park transformation based on the motor model equation in the three-phase stationary coordinate system. The stator and rotor voltage equations are:

$$
\left\{\begin{array}{l}
u_{s \mathrm{~d}}=R_{s} i_{s d}+\frac{d \psi_{s d}}{d t}-\psi_{s q} \frac{d \theta_{1}}{d t} \\
u_{s q}=R_{s} i_{s q}+\frac{d \psi_{s q}}{d t}+\psi_{s d} \frac{d \theta_{1}}{d t} \\
u_{r d}=R_{r} i_{r d}+\frac{d \psi_{r d}}{d t}-\psi_{r q} \frac{d \theta_{2}}{d t} \\
u_{r q}=R_{r} i_{r q}+\frac{d \psi_{r q}}{d t}+\psi_{r d} \frac{d \theta_{2}}{d t}
\end{array}\right.
$$

The stator and rotor flux equations are:

$$
\left\{\begin{array}{l}
\psi_{s \mathrm{~d}}=L_{s} i_{s d}+L_{m} i_{r d} \\
\psi_{s q}=L_{s} i_{s q}+L_{m} i_{r q} \\
\psi_{r d}=L_{r} i_{r d}+L_{m} i_{s d} \\
\psi_{r q}=L_{r} i_{r q}+L_{m} i_{s q}
\end{array}\right.
$$

The electromagnetic torque equations is:

$$
T_{e}=\frac{P_{m} L_{m}}{L_{r}}\left(i_{s q} \psi_{r d}-i_{s d} \psi_{r q}\right)
$$

Where $u_{s \mathrm{~d}}, u_{s q}, u_{r d}, u_{r q}$ are the $\mathrm{d}$ and q axis voltage; $i_{s d}$, $i_{s q}, i_{r d}, i_{r q}$ are the $\mathrm{d}$ and $\mathrm{q}$ axis current; $\psi_{s d}, \psi_{s q}, \psi_{r d}, \psi_{r q}$ are the $\mathrm{d}$ and $\mathrm{q}$ axis current flux; $R_{s}, R_{r}$ represent stator and rotor resistance; $L_{s}, L_{r}, L_{m}$ stator and rotor self-inductance and mutual inductance between them; $\theta_{1}$ and $\theta_{2}$ are represent the angle between the $\mathrm{d}$ and $\mathrm{q}$ axis and the $\alpha$ axis of the stationary two phase coordinate system respectively; $T_{e}$ is electromagnetic torque; $P_{m}$ is polar logarithm.

\section{Speed sensorless control method based on MRAS}

Speed sensorless control strategy eliminates the speed sensor with shortcomings such as low reliability. It obtains the motor speed through a certain algorithm using the motor stator voltage, current and other electrical signals which easily measured. The key to the problem is how to estimate the speed information quickly, and maintain high control accuracy, which can meet the requirements of real-time control.

Figure3 is the basic structure of Model Reference Adaptive System(MRAS). As the most widely used speed estimation method, the basic idea of MRAS is as follows. It designs the adaptive control system using Popov stability theory in the two phase static coordinate asynchronous motor system where the rotor flux voltage model without speed as the reference model and the current model of rotor flux with speed as the adjustable model[11].

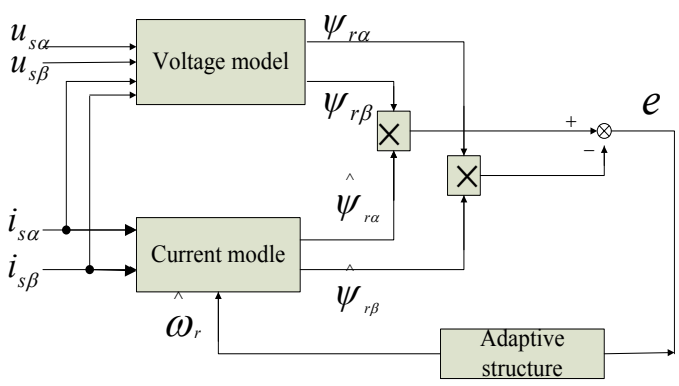

Figure 3. the basic structure of motor MRAS

The key to MRAS is the selection of adaptive law. In general, the speed is time-varying. But because of the inertia of the transmission system, in the small range of instantaneous speed change, it can be assumed that all the parameters are constant except the rotational speed as the variable to be identified. The estimated value of the current model is the equation(4). 


$$
p\left[\begin{array}{l}
\hat{\psi}_{r \alpha} \\
\hat{\psi}_{r \beta}
\end{array}\right]=\left[\begin{array}{cc}
-T_{\mathrm{r}} & -\hat{\omega}_{r} \\
\hat{\omega}_{r} & -T_{\mathrm{r}}
\end{array}\right]\left[\begin{array}{l}
\hat{\psi}_{r \beta} \\
\hat{\psi}_{r \alpha}
\end{array}\right]+L_{m} T_{r}\left[\begin{array}{c}
i_{s \alpha} \\
i_{s \beta}
\end{array}\right]
$$

Define state error $e=\psi_{r}-\hat{\psi}_{r}$ and We can obtain error equation (5) from the difference between the actual model and the estimated model.

$$
p\left[\begin{array}{l}
e_{r \alpha} \\
e_{r \beta}
\end{array}\right]=\left[\begin{array}{ll}
-T_{\mathrm{r}} & -\omega_{r} \\
-\omega_{r} & -T_{\mathrm{r}}
\end{array}\right]\left[\begin{array}{l}
e_{r \alpha} \\
e_{r \beta}
\end{array}\right]-\left(\hat{\omega}_{r}-\omega_{r}\right)\left[\begin{array}{cc}
0 & -1 \\
-1 & 0
\end{array}\right]\left[\begin{array}{l}
\hat{\psi}_{r \alpha} \\
\hat{\psi}_{r \beta}
\end{array}\right](5)
$$

Put it another form:

$$
\dot{e}=A_{\mathrm{m}} e-\omega
$$

According to the Popov inequality, the identification model of rotational speed can be obtained under the premise that $\eta(0, t) \geq-\gamma^{2}$ is established:

$$
\begin{aligned}
& \hat{\omega}_{r}=\int_{0}^{\mathrm{t}} K_{1}\left(\hat{\psi}_{r \alpha} \psi_{r \beta}-\psi_{\mathrm{r} \alpha} \hat{\psi}_{r \beta}\right) d t+K_{p}\left(\hat{\psi}_{r \alpha} \psi_{r \beta}-\psi_{\mathrm{r} \alpha} \hat{\psi}_{r \beta}\right) \\
& +\hat{\omega}(0)=\left(K_{p}+K_{1} / \mathrm{s}\right)\left(\hat{\psi}_{r \alpha} \psi_{r \beta}-\psi_{\mathrm{r} \alpha} \hat{\psi}_{r \beta}\right)
\end{aligned}
$$

\section{Simulation analysis based MATLAB/Simulink}

In order to verify the feasibility of induction motor speed sensorless vector control system based on MRAS, the simulation experiment is carried out by using the mentioned methods in MATLAB/Simulink. The main parameters of the asynchronous motor used in the experiment are listed in Table 1:

Table 1. motor parameters

\begin{tabular}{|c|c|}
\hline Parameters & Values \\
\hline Line voltage $U$ & $380 \mathrm{~V}$ \\
\hline Rated frequency $f$ & $50 \mathrm{~Hz}$ \\
\hline Number of pole pairs $P_{n}$ & 4 \\
\hline Stator resistance $R_{s}$ & $0.253 \Omega$ \\
\hline Rotor resistance $R_{r}$ & $0.531 \Omega$ \\
\hline Self inductance of Stator $L_{s}$ & $0.102 \mathrm{mH}$ \\
\hline Self inductance of rotor $L_{r}$ & $0.052 \mathrm{mH}$ \\
\hline Mutual inductance $L_{m}$ & $0.053 \mathrm{mH}$ \\
\hline Inertia $J$ & $0.22 \mathrm{~kg} \cdot \mathrm{m}^{2}$ \\
\hline
\end{tabular}

\subsection{Simulation model}

On the basis of analyzing the mathematical model of threephase asynchronous motor, a simulation model of current hysteresis vector control system based on speed sensorless is established. The system adopts double closed loop structure, and the speed, torque and flux control adopt PI regulator with integral and output limiting, and the current is controlled by hysteresis. The system model includes rotor flux observation subsystem, speed estimation subsystem (figure 4), current hysteresis PWM subsystem (figure 5) and so on. The whole control system is shown in figure6. The whole system is simulated by continuous control system.

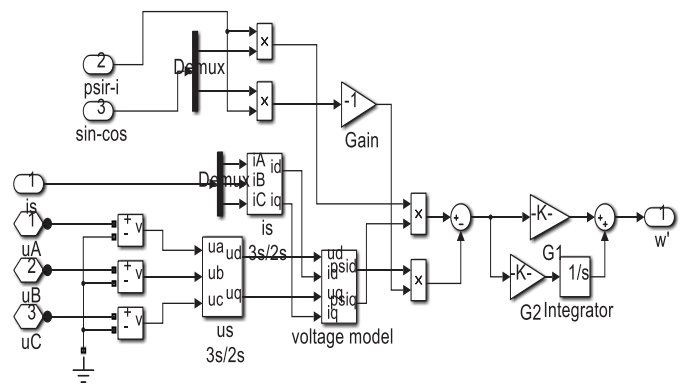

Figure 4. Speed estimation module

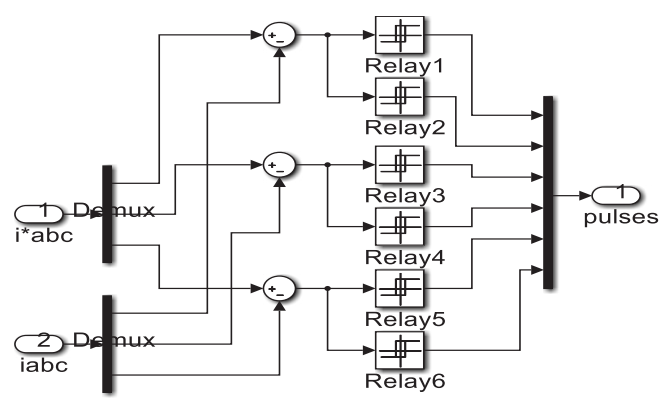

Figure 5. Hysteresis-band current PWM output module

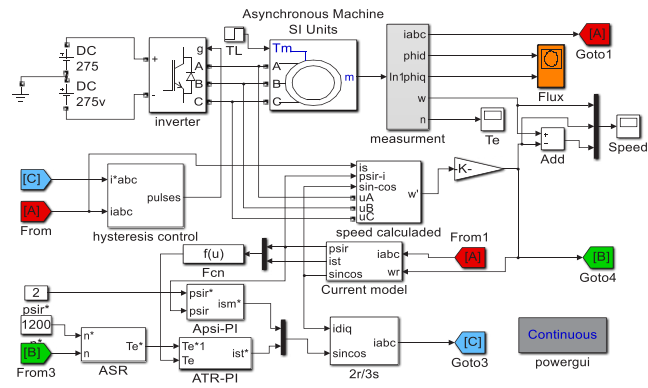

Figure 6. Speed sensorless vector control system

The parameter settings of the PI regulator are shown in Table2.

Table 2. regulator parameters

\begin{tabular}{|c|c|c|c|c|}
\hline \multirow{2}{*}{$\begin{array}{c}\text { PI } \\
\text { Regulator }\end{array}$} & $\mathbf{K}_{\mathbf{p}}$ & $\mathbf{K}_{\mathbf{i}}$ & \multicolumn{2}{|c|}{$\begin{array}{c}\text { Regulator } \\
\text { clipping }\end{array}$} \\
\cline { 3 - 5 } & $\begin{array}{c}\text { Upper } \\
\text { limit }\end{array}$ & $\begin{array}{c}\text { lower } \\
\text { limit }\end{array}$ \\
\hline $\begin{array}{c}\text { Speed } \\
\text { regulator }\end{array}$ & 12 & 3.2 & 80 & -80 \\
\hline $\begin{array}{c}\text { Torque } \\
\text { regulator }\end{array}$ & 5.5 & 18 & 55 & -55 \\
\hline $\begin{array}{c}\text { Flux } \\
\text { regulator }\end{array}$ & 3 & 125 & 16 & -16 \\
\hline $\begin{array}{c}\text { Speed } \\
\text { estimation }\end{array}$ & 1.28 & 385 & - & - \\
\hline
\end{tabular}

\subsection{Simulation analysis}

In order to verify the static and dynamic performance of the system, the current and speed change of the motor under sudden load are given, and the accuracy of the speed estimation is also observed. In the simulation, the initial speed is set to 1200rpm, the motor is unloaded at startup, 
and the load torque is added to $45 \mathrm{~N} \cdot \mathrm{m}$ after $0.6 \mathrm{~s}$. The simulation waveform is shown in figure 7 .

Through the waveform, it can be seen that the motor reaches a given speed at about 0.40 second after starting, and the no-load torque is about 0 and the fluctuation is smaller after steady state. When the torque is suddenly increased, the speed is basically kept at a given speed, and the torque of the motor reaches the load torque rapidly and tends to be stable.

Through the analysis, the vector control system has good response speed, and the speed control is more accurate. In the estimation of speed, it can be seen from figure 7(d) that the actual speed is almost the same as the estimated speed after steady state, and the speed estimation is still accurate after sudden load torque. In the early stage of speed rise there will be some deviation, this is mainly because of the changing current in the early, and There is a time delay in the adjustable model, which makes the current change with certain delay and is amplified in its rapid change

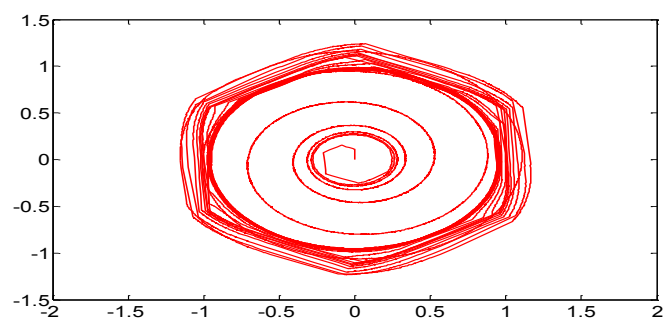

(a)stator flux linkage

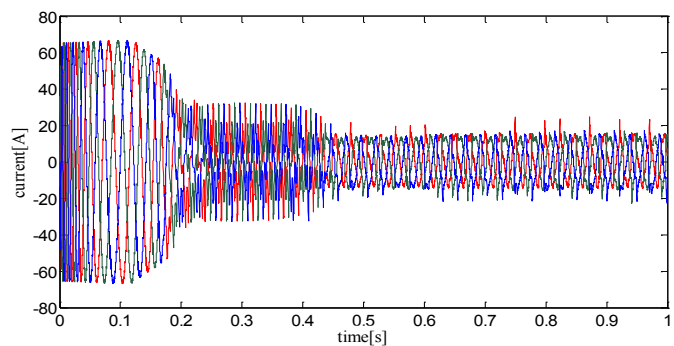

(b)three-phase stator current

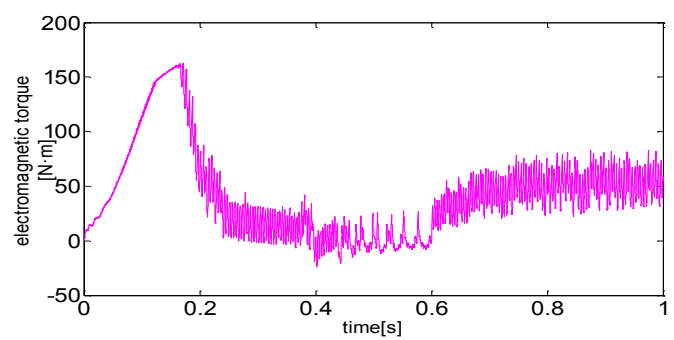

(c)electromagnetic torque

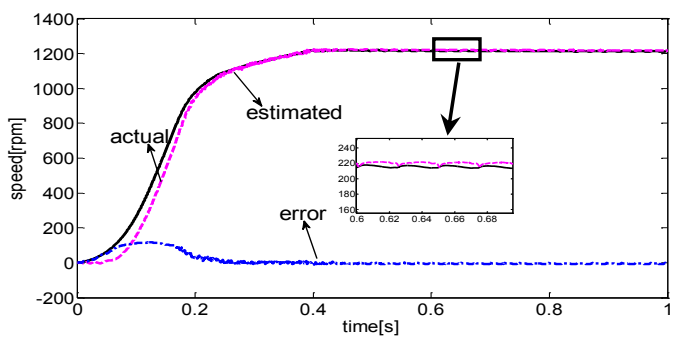

(d)actual and estimated speed

Figure 7. Performance under load of MRAS system
Figure 8 is the speed sensorless vector control Counterstarting and steering process. Figure8(a) is the flux linkage curve which showing a well circle, indicating that the system pulsation is small. From 0 to 0.15 second is the Counter-starting process of the motor. In the starting process, the speed calculated by the speed observer has a certain deviation from the speed measured by the measuring module. From 0.15 to 0.3 second is the reverse stable phase, and at the time 0.3 second, the system switched to positive 500rpm, the motor speed began to decline, and quickly entered the positive start stage. As shown in figure 8(c), the motor always keeps the maximum torque until the start is completed. Looking at figure8(d), there is almost no difference between the observed rotational speed and the steady speed in the two stable stages.

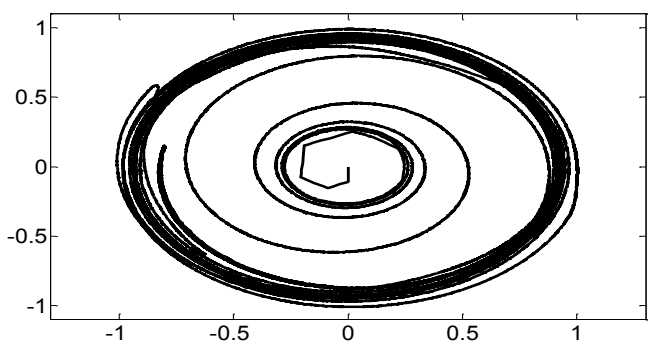

(a) stator flux linkage

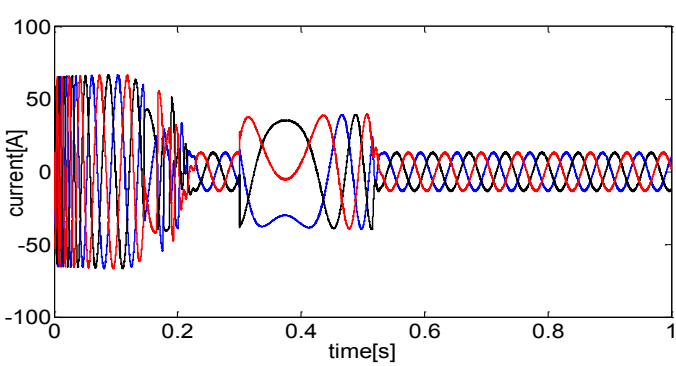

(b) three-phase stator current

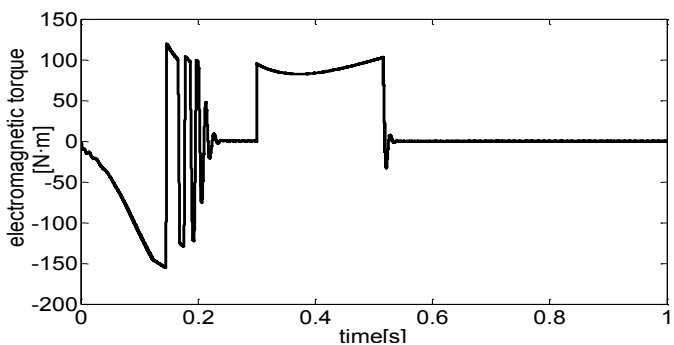

(c) electromagnetic torque

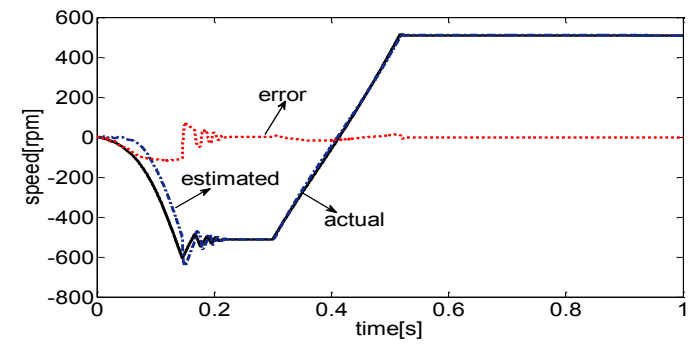

(d) actual and estimated speed

Figure 8. Positive and negative adjustment process of MRAS system 


\section{Conclusion}

In this paper, the basic principle of vector control is analyzed. Based on MRAS speed identification method, a speed sensorless vector control system is built in MATLAB/Simulink. By analyzing the simulation waveform, it is proved that the system has good dynamic and static performance, and the speed identification is feasible. Compared with the installation of speed controller, this control method can not only improve the reliability of the system, but also save a part of the cost, which has certain value for practical engineering application.

\section{References}

1. A. Mecke, I. Lee, J.R. Baker jr., M.M. BanaszakHoll, B.G. Orr, Eur. Phys. J. E 14, 7 (2004)

1. P.F. Zheng, T. Fukao. Robust speed identification for speed-sensorless vector control of induction motors. IEEE Transactions on Industry Applications.J. 30,5:1234-1240(1994)

2. T.N. Ohtani, Takada, K. Tanaka. Vector control of induction motor without shaft encoder. Industry Applications IEEE Transactions.J. 28, 1:157164(1992)

3. Y.R. Kim, S. K. Sul, M. H. Park. Speed sensorless vector control of induction motor using extended Kalman filter. Industry Applications IEEE Transactions. J. 30, 5:1225-1233(1994)
4. Yao, Qing Hua, M. Cao. Research of Vector Control for Asynchronous Motor System Based on MRAS.Key Engineering Materials. J.:769-772 (2013)

5. E. D.Mitronikas, A. N. Safacas. An improved sensorless vector-control method for an induction motor drive. IEEE Transactions on Industrial Electronics.J.52,6:1660-1668(2005)

6. Dwivedi, Anurag, A. N. Tiwari. Analysis of threephase PWM rectifiers using hysteresis current control techniques: a survey. International Journal of Power Electronics.J.8,4: 349(2017)

7. V. Neenu. Adaptive Modified Hysteresis Current Controlled Grid Connected Photovoltaic Inverter. International Journal of Engineering \& Technical Research.J. 6, 4(2017).

8. L.Zhen, L. Xu. Sensorless field orientation control of induction machines based on a mutual MRAS scheme. Industrial Electronics IEEE Transactions.J.45,5 : 824831(1998)

9. E. Levi, R. Bojoi, F. Profumo. Multiphase induction motor drives - a technology status review. Iet Electric Power Applications.J.4,1: 489-516 (2007)

10. M. Cirrincione, M. Pucci. An MRAS-based sensorless high-performance induction motor drive with a predictive adaptive model. IEEE Transactions on Industrial Electronics.J.52.2:532-551(2005)

11. M. Jain, M. Singh, A. Chandra, S.S. Williamson, Sensorless control of permanent magnet synchronous motor using ANFIS based MRAS.Electric Machines \& Drives ConferenceIEEE, C. :599-606 (2011) 